\title{
AIAA 99-3759 \\ Breakup of Turbulent Liquid Jets in Still Gases
}

K.A. Sallam, Z. Dai and G.M. Faeth

Department of Aerospace Engineering

The University of Michigan

Ann Arbor, MI 48109-2140

\section{0th AIAA Fluid Dynamics Conference 28 June - 1 July, 1999 / Norfolk, VA}




\title{
BREAKUP OF TURBULENT LIQUID JETS IN STILL GASES
}

\author{
K. A. Sallam, ${ }^{*}$ Z. Dai ${ }^{\dagger}$ and G. M. Faeth ${ }^{\ddagger}$ \\ The University of Michigan, Ann Arbor, MI 48109-2140
}

\begin{abstract}
An investigation of the breakup lengths of turbulent liquid jets in still gases is described. Different breakup modes were visualized and mean and fluctuating breakup lengths were measured for round turbulent free jets of water and ethanol in still air at standard temperature and pressure. Jet exit conditions were limited to non-cavitating flows with long length/diameter ratio constant area injector passages and jet exit Reynolds numbers of 6,000140,000 . Two turbulent liquid column breakup modes were observed: a turbulent primary breakup mode observed at small Weber numbers and a bag/shear breakup mode observed at large Weber numbers. The turbulent primary breakup mode was successfully associated with existing theories of this process as the condition where drop sizes resulting from turbulent primary breakup are comparable to the diameter of the liquid column itself. The bag/shear breakup mode was observed when liquid turbulence caused large deformations of the liquid column, placing portions of the column in cross flow; this caused bag or shear breakup of the liquid column as a whole which was successfully associated with existing theories of bag and shear breakup of nonturbulent round liquid jets in cross flowing gases.
\end{abstract}

\section{NOMENCLATURE}

$\mathrm{C}_{\mathrm{bs}}=$ bag/shear breakup coefficient
$\mathrm{C}_{\mathrm{c}}=$ turbulent liquid column breakup
$\mathrm{C}_{\mathrm{sx}}=$ coefficient
$\mathrm{d}=$ jurbulent primary breakup coefficient
$\mathrm{d}_{\mathrm{h}}=$ jet exit diameter

"Graduate Student Research Assistant, Department of Aerospace Engineering.

'Engineering Research Associate, Department of Aerospace Engineering.

${ }^{\ddagger}$ A.B. Modine Professor, Department of Aerospace Engineering, Fellow AIAA.

Copyright (C) 1999 by G. M. Faeth. Published by the American Institute of Aeronautics and Astronautics, Inc., with permission.

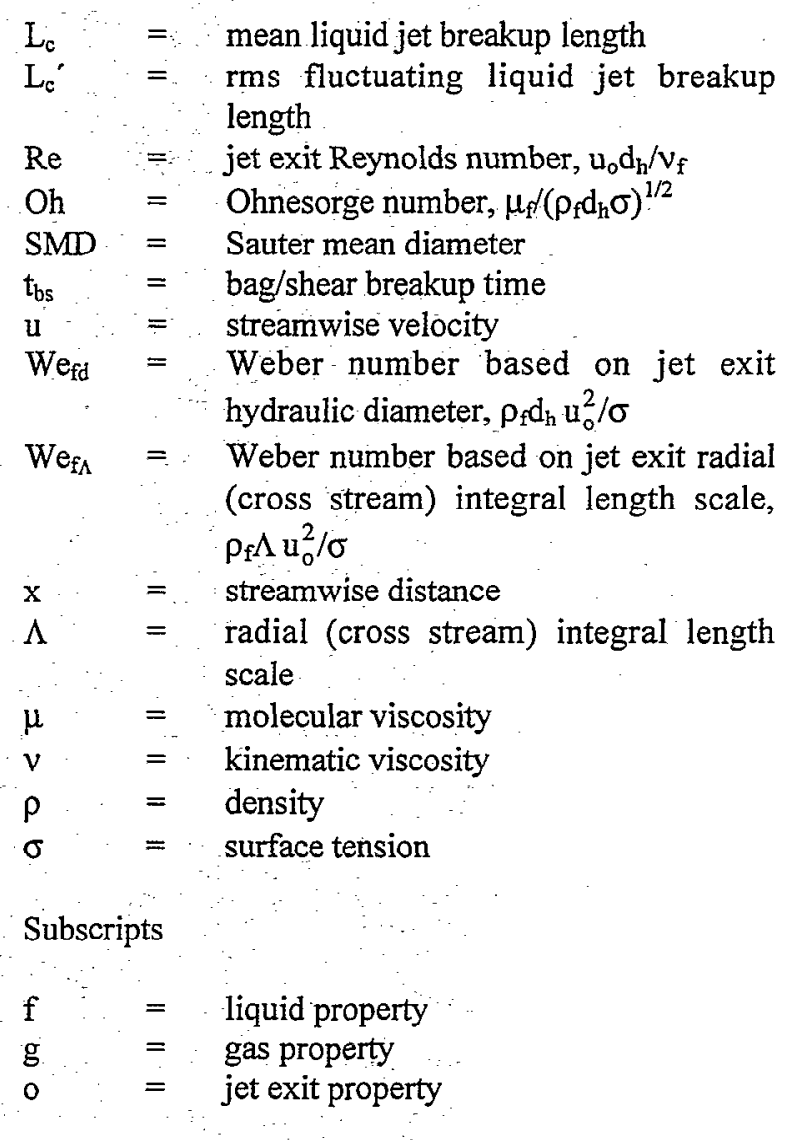

\section{INTRODUCTION}

The breakup length of turbulent liquid jets in still gases was studied experimentally. This breakup process is related to turbulent primary breakup which can dominate spray formation for a variety of industrial and natural phenomena, e.g., spray atomization, liquid jets, plunge pools, bow sheets, breaking waves and water falls, among others. ${ }^{1-12}$ Breakup lengths are of interest for spray modeling efforts because the breakup location signals the end of the "so-called" dense spray region and the start of the generally dilute dispersed-flow region. ${ }^{13}$ Liquid breakup lengths also are of interest for gaining insight about the properties of turbulent primary breakup along liquid surfaces. Experimental methods used during this study were similar to past 
investigations of turbulent primary breakup by the present authors and their associates. ${ }^{14-19}$

Earlier studies of the length of turbulent liquid jets in still gases have been mainly limited to round jets and include the experimental studies of Chen and Davis, ${ }^{5}$ Grant and Middleman, ${ }^{6}$ Phinney, and McCarthy and Malloy. ${ }^{8}$ Using available data, Grant and Middleman, ${ }^{6}$ developed a reasonably effective correlation of existing measurements of mean liquid jet lengths based on dimensional analysis. Subsequently, $\mathrm{Wu}$ and coworkers ${ }^{14-17}$ reported a more mechanistic approach for correlating the mean length of round turbulent liquid jets in still gases. This approach was based on phenomenological analysis of turbulent primary drop breakup along the liquid surface, assuming that drops were formed from turbulent eddies of comparable size for conditions where the eddies responsible for drop formation were in the inertial and large-eddy subranges of the turbulence spectrum. This approach yielded effective correlations for the onset and end of drop formation and for drop sizes as a function of distance along the surface for turbulent primary breakup. ${ }^{14,17}$ These results showed that drop sizes progressively increased with increasing distance along the surface and suggested that the end of the liquid core was reached when the diameters of drops formed by turbulent primary breakup were roughly equal to the initial diameter of the liquid jet itself. ${ }^{14}$ Subsequent evaluation of this concept for round liquid jets was promising, ${ }^{17}$ based on measurements using present methods as well as earlier measurements due to Chen and Davis ${ }^{5}$ and Grant and Middleman. ${ }^{6}$

One concern about the previous finding involved potential aerodynamic effects that were known to affect turbulent primary breakup properties due to the merging of primary and secondary breakup for some operating conditions. ${ }^{15}$ Another concern was potential effects of weakly-developed turbulence when jet exit Reynolds numbers were small. ${ }^{16}$ Thus, the objectives of the present investigation were to complete additional observations of the breakup lengths of turbulent liquid jets in order to assess the earlier findings, and to carry out measurements where aerodynamic and small Reynolds number effects were anticipated in order to help resolve both the properties and limitations of the turbulent liquid column breakup mechanism. Present observations were limited to round liquid jets in still air at standard temperature and pressure with jet exit conditions limited to non-cavitating flows with large length/diameter ratio constant area injector passages.

\section{EXPERIMENTAL METHODS}

\section{Apparatus}

Pressure injection was used to feed the test liquid from a cylindrical storage chamber into a round nozzle directed vertically downward as illustrated in Fig. 1. The storage chamber had an inside diameter and length of 190 and $305 \mathrm{~mm}$, respectively. The nozzle had a smooth rounded entry (radius of curvature equal to the nozzle passage radius) followed by round, constant-area passages having length-to-diameter ratios greater than $40: 1$ to help ensure fully-developed turbulent pipe flow at the jet exit, see Ref. 16 and references cited therein.

Liquid was placed in the storage chamber through a port with premature outflow prevented by a cork in the nozzle exit. The liquid was forced through the nozzle, ejecting the cork, by admitting high-pressure air to the top of the storage chamber through a solenoid valve. A baffle at the air inlet prevented undesirable mixing between the air and the test liquid. The high pressure air was stored in an accumulator having a volume of $0.12 \mathrm{~m}^{3}$ on the upstream side of the solenoid valve, with provision for accumulator air pressures up to $1.9 \mathrm{MPa}$. The test liquid was captured in a baffled tub. The nozzle assembly could be traversed vertically with an accuracy of $0.5 \mathrm{~mm}$ using a linear bearing system in order to accommodate rigidly-mounted optical instrumentation.

Injection times of $100-400 \mathrm{~ms}$ were long compared to flow development times of $6-70 \mathrm{~ms}$. Present optical measurements required less than 0.1 $\mathrm{ms}$ for triggering and data acquisition which did not impose any limitations on flow times. Jet velocities were calibrated in terms of nozzle pressure drop by measuring liquid surface velocities using doublepulse shadowgraphs as discussed later.

\section{Instrumentation}

Instrumentation consisted of single- and double-pulse shadowgraphy using an arrangement similar to Dai et al. ${ }^{18}$ Two frequency-doubled YAG lasers were used for the light sources; their operation could be controlled to provide pulse separations as small as 100 ns. The shadowgraphs were recorded using a $100 \times 125 \mathrm{~mm}$ film format with magnification of these records ranging up to $7: 1$. The photographs were obtained with an open camera shutter under darkroom conditions so that the $7 \mathrm{~ns}$ pulse duration controlled the exposure time and was sufficiently short to stop liquid surface motion. 
Several images were averaged in order to find mean and rms fluctuating liquid column breakup lengths with experimental uncertainties $(95 \%$ confidence) less than 5 and $20 \%$, respectively, mainly dominated by sampling limitations. Measurements of liquid surface velocities were based on the motion of particular points along ligaments and other surface irregularities while summing over $40-200$ points to find surface velocities with experimental uncertainties ( $95 \%$ confidence) less than $10 \%$, also mainly dominated by sampling limitations.

\section{Test Conditions}

Present test conditions are summarized in Table 1. The test liquids were water and ethanol with 1.9 and $4.8 \mathrm{~mm}$ initial jet diameters. Other experimental parameters can be summarized as follows: $u_{\mathrm{o}}$ of $3-54 \mathrm{~m} / \mathrm{s}, \operatorname{Re}_{\mathrm{fd}}$ of $6000-136,000, \mathrm{We}_{\mathrm{fd}}$ of 200-300000, $\mathrm{Oh}_{\mathrm{d}}$ of $0.0015-0.0053$ and $\mathrm{L}_{\mathrm{c}} / \mathrm{d}$ of $50-$ 300. The Reynolds number range implies that the present results were dominated by effects of turbulent primary breakup, except as noted later. The small jet exit Ohnesorge numbers imply that direct effects of liquid viscosity on liquid breakup were small. Present measurements were also supplemented by the earlier results of Chen and Davis, ${ }^{5}$ and Grant and Middleman, ${ }^{6}$ as noted later.

\section{RESULTS AND DISCUSSION}

\section{Turbulent Breakup Process}

Two types of turbulent liquid column breakup were observed, as follows: one at moderate Weber numbers, denoted the turbulent breakup process, associated with turbulent primary breakup along liquid surfaces similar to the observations of Chen and Davis, ${ }^{5}$ Grant and Middleman, ${ }^{6}$ and Wu and Faeth; ${ }^{17}$ the other at relatively large Weber numbers, denoted the bag/shear breakup process, associated with aerodynamic effects analogous to the secondary breakup of drops ${ }^{20-22}$ and the primary breakup of nonturbulent liquid jets in gaseous cross flows. ${ }^{23-24}$ Flow visualization and phenomenological analysis to develop breakup length correlations will be considered for each of these mechanisms in the following.

The typical appearance of the turbulent liquid jets and the turbulent breakup process at moderate values of $W e_{\mathrm{fd}}$ are illustrated in Fig. 2 . This condition yields a liquid column whose surface is distorted by turbulence with the liquid column breakup process associated with liquid disturbances having characteristic dimensions comparable to the diameter of the liquid column itself. Thus, liquid column breakup at these conditions appears to involve the turbulent primary breakup mechanism proposed by Wu et al. ${ }^{14-16}$

Turbulent primary breakup when aerodynamic effects are small, proposed by $\mathrm{Wu}$ et al., ${ }^{14,16}$ involves the formation of drops at the surface of a turbulent liquid. This mechanism of drop formation results from the distortion of the liquid surface by turbulent eddies, leading to the formation of drops of comparable size, given sufficient turbulence energy to supply the surface tension energy of the corresponding drop and sufficient time for the eddy to deform the surface to the extent needed to form a drop. ${ }^{14,16}$ Past measurements of drop sizes formed by this primary breakup mechanism are plotted in Fig. 3 as suggested by phenomenological analysis of the turbulent primary breakup process. Measurements shown in the figure include results for turbulent round free jets, ${ }^{14}$ turbulent plane free jets, ${ }^{19}$ and turbulent plane wall jets, ${ }^{18}$. Also shown on the plot is a correlation of round turbulent liquid column breakup lengths developed using dimensional analysis by Grant and Middleman, ${ }^{6}$ as follows:

$$
\mathrm{L}_{\mathrm{c}} / \mathrm{d}=8.51 \mathrm{We}_{\mathrm{fd}}^{0.32}
$$

where the range of $L_{c} / d$ shown on the figure results from the variation of $W_{\text {fd }}$ over the range of the measurements of $\mathrm{Wu}$ et al. ${ }^{14,16}$

Two trends of the measurements and correlations illustrated in Fig. 3 are of interest for gaining a better understanding of turbulent primary breakup. First of all, drop sizes after turbulent primary breakup (represented by the SMD) progressively increase with increasing distance along the surface. This behavior comes about because larger drops require progressively more time to form, and thus travel a larger distance along the surface as they convect for their drop formation time. Another effect supporting this behavior is that smaller eddies, which create smaller drops, decay away before the larger drops can form. The second observation of interest is that the drop sizes resulting from turbulent primary breakup become comparable to the diameter of the liquid column itself for the range of conditions where the correlation of Grant and Middleman, ${ }^{6}$ predicts liquid column breakup.

The observations just discussed in connection with Fig. 3 suggest associating turbulent liquid column breakup with conditions where drop sizes after turbulent primary breakup are comparable 
to the diameter of the liquid column. ${ }^{17}$ This can be done using the correlation for drop sizes after turbulent primary breakup obtained from phenomenological analysis, as follows: ${ }^{19}$

$$
\mathrm{SMD} / \Lambda=\mathrm{C}_{\mathrm{sx}}\left(\mathrm{x} /\left(\Lambda \mathrm{W} \mathrm{e}_{\mathrm{f} \Lambda}^{1 / 2}\right)\right)^{2 / 3}
$$

where $C_{\mathrm{sx}}=0.65$ based on the measurements of Wu et al. ${ }^{14}$ Then assuming that $\mathrm{SMD} \sim \mathrm{d}$ at liquid column breakup, where $x=L_{c}$, Eq. (2) yields:

$$
\mathrm{L}_{\mathrm{c}} / \mathrm{d}=\mathrm{C}_{\mathrm{c}} \mathrm{We}_{\mathrm{fd}}^{1 / 2}
$$

where $C_{c}$ is an empirical parameter on the order of unity. The similarity between Eq. (2), based on dimensional analysis of earlier measurements of turbulent liquid column breakup lengths, and Eq. (3) based on consideration of turbulent primary breakup processes, is encouraging. Thus, Eq. (3) was explored as a more mechanistic way of correlating turbulent liquid column breakup lengths.

\section{Bag/Shear Breakup Process}

When values of $W e_{f d}$ exceed the upper end of the range of measurements considered by Chen and Davis, ${ }^{5}$ and Grant and Middleman, ${ }^{6}$ the turbulent liquid column breakup mechanism changes. A low magnification photograph of the new large Weber number breakup process is illustrated in Fig. 4. In this case, large-scale turbulence distorts the liquid column to a much greater degree than during the turbulent liquid column breakup process at moderate Weber numbers illustrated in Fig. 2. Then for the conditions illustrated in Fig. 4, bag-like structures appear along the deformed liquid column that are similar to the bag-like structures formed near the onset of the secondary breakup of drops due to shock-wave disturbances ${ }^{20-22}$ and the breakup of nonturbulent round liquid jets in cross flowing gases. $^{23,24}$ This behavior suggests a somewhat surprising aerodynamic effect on breakup of the liquid column as a whole; namely, as transition to nonturbulent liquid column breakup in cross flow as opposed to an effect related to merging of primary and secondary breakup as seen for turbulent primary breakup along surfaces. ${ }^{15}$

A closer view of acrodynamic liquid column breakup of turbulent liquid jets can be seen in the pulsed shadowgraph photographs of Figs. 5-7. Figure 5 is an illustration of the cross stream distortion just prior to aerodynamic liquid column breakup. Typical of turbulent primary breakup, the small-scale liquid surface distortions due to small- scale eddies, seen nearer to the jet exit (e.g., Fig. 2) are absent because all the small-scale eddies have decayed. Thus, all that remains are large-scale distortions of a nearly nonturbulent liquid column. This places most liquid column elements in cross flow which leads to modes of breakup similar to those observed during the breakup of a nonturbulent liquid column in a gaseous cross flow, ${ }^{23,24}$ e.g., the bag-type breakup seen in Fig. 4. Two types of breakup of the liquid column in this manner were observed as illustrated in the close up photographs of Figs. 5 and 6; namely, bag-type column breakup (Fig. 5) and shear-type column breakup (Fig. 6). Notably, both these modes of liquid column breakup were observed by Mazallon et al. ${ }^{24}$ for nonturbulent liquid column breakup in cross flowing gases; thus, the mechanism is clearly associated with an aerodynamic effect.

A simplified phenomenological analysis can provide some insight about the bag/shear breakup process and a convenient way of correlating these breakup lengths. First of all, by analogy to the secondary breakup of drops, the time required for bag or shear breakup of the liquid column is given by: ${ }^{24}$

$$
t_{b s}=C_{b s}\left(\rho_{f} / \rho_{g}\right)^{1 / 2} d / u_{0}
$$

where $C_{b s}$ is an empirical parameter on the order of unity. Based on past findings for secondary drop breakup, the value of $\mathrm{C}_{\mathrm{bs}}$ is not expected to differ very much with changes of the specific breakup mode, e.g., bag-type or shear-type breakup. ${ }^{20-22}$ Now assume that the point of breakup corresponds to the streamwise distance reached by the column while moving at the mean jet exit velocity for a time, $t_{b s}$, as follows:

$$
\mathrm{L}_{\mathrm{c}}=\mathrm{u}_{\mathrm{o}} \mathrm{t}_{\mathrm{bs}}
$$

Combining Eqs. (4) and (5) yields an expression for the bag/shear breakup length, as follows:

$$
\mathrm{L}_{\mathrm{c}} / \mathrm{d}=\mathrm{C}_{\mathrm{bs}}\left(\rho_{\mathrm{f}} / \rho_{\mathrm{g}}\right)^{1 / 2}
$$

where it is also required that the flow leaving the jet exit is turbulent. This result suggests that $\mathrm{L}_{\mathrm{c}} / \mathrm{d}$ first increases with increasing $W e_{\mathrm{fd}}$ according to Eq. (3) and then becomes independent of $\mathrm{We}_{\mathrm{fd}}$ at large values of this parameter (at conditions specifically governed by $\rho_{\mathrm{f}}\left(\rho_{\mathrm{g}}\right)$.

The liquid jet breakup length correlation of Eq. (6) is identical to early correlations of liquid jet breakup lengths measured at large pressures by Hiroyasu et al. ${ }^{25}$ and Chehoudri et al. ${ }^{26}$ Their test 
conditions, however, imply relatively small values of $\mathrm{L}_{d} / \mathrm{d}$ where distortion of the entire liquid column in the manner illustrated in Figs. 4-7 is improbable. Instead, the high-pressure aerodynamic mechanism is much more likely to involve merging of turbulent primary breakup and secondary breakup of ligaments protruding from the liquid surface, as discussed by $\mathrm{Wu}$ et al. ${ }^{15}$ This mechanism only appears for pressures somewhat greater than atmospheric pressure, ${ }^{15}$ however, and was not a factor during the present investigation.

\section{Mean Breakup Lengths}

In order to assess ideas about the turbulent and bag/shear liquid column breakup processes, present and past measurements of $L_{c} / d$ are plotted as a function of $\mathrm{We}_{\mathrm{fd}}$ in Fig. 8. Measurements shown on this plot include results from Chen and Davis, ${ }^{5}$ Grant and Middleman, ${ }^{6}$ and the present investigation. Several correlations of the measurements are also shown on the plot, as follows: (1) the correlation of Eq. (1) due to Grant and Middleman, ${ }^{6}$ based on the measurements of Refs. 5 and 6 for We $\mathrm{fd}_{\mathrm{fd}}$ of $10^{2}-10^{5}$; (2) the best fit correlation of turbulent breakup theory based on Eq. (3),

$$
\mathrm{L}_{\mathrm{d}} / \mathrm{d}=2.1 \mathrm{We}_{\mathrm{fd}}^{1 / 2}
$$

where the standard deviation of the coefficient is 0.2 , based on the present measurements for $\mathrm{We}_{\mathrm{fd}}$ of 700 30,000 ; and (3) the best fit correlation of bag/shear breakup theory based on Eq. (6),

$$
\mathrm{L}_{\mathrm{c}} / \mathrm{d}=11.0\left(\rho_{\mathrm{f}} / \rho_{\mathrm{g}}\right)^{1 / 2}
$$

where the standard deviation of the coefficient is 0.3 , based on the present measurements for ethanol with $W_{\mathrm{fd}}$ greater than 100,000 . Another correlation illustrated on the plot is for bag/shear breakup of water jets computed from Eq. (8).

Present measurements, and those of Chen and Davis ${ }^{5}$ and Grant and Middleman, ${ }^{6}$ of $\mathrm{L}_{\mathrm{c}} / \mathrm{d}$ in Fig. 8 are in excellent agreement for the range of conditions where they can be compared. The Grant and Middleman, ${ }^{6}$ expression for $\mathrm{L}_{d} / \mathrm{d}$ given by Eq. (1) is also seen to provide a good correlation of the measurements over the range of $\mathrm{We}_{\mathrm{fd}}$ that they considered. Closer examination, however, suggests that this performance may be an artifact of transition from turbulent breakup to different breakup mechanisms at the large and small $W e_{\mathrm{fd}}$ ranges of the measurements. For example, at small $\mathrm{We}_{\mathrm{fd}}$, jet Reynolds numbers become small, approaching values of 2000 so that effects of weakly-developed turbulence become a factor; this is supported by transitional-like behavior where the measurements shift from the Grant and Middleman, ${ }^{6}$ correlation for $\mathrm{We}_{\mathrm{fd}}$ smaller than 400 to the present turbulent breakup correlation for $W e_{\text {fd }}$ larger than 800 (the corresponding transitional range of $R e$ is $5000-25000$ which is supportive of effects of weakly-developed turbulence $\left.{ }^{16}\right)$. Additional evidence of an effect of laminar-like behavior at small $\mathrm{We}_{\mathrm{fd}}$ was obtained by direct flow visualization using pulsed shadowgraphy; not surprisingly, these photographs showed that breakup involved regular Rayleigh-like breakup of a smooth liquid column for the smallest $W_{e_{f d}}$ considered in Fig. 8.

At the other extreme, $\mathrm{L}_{\mathrm{c}} / \mathrm{d}$ proved to be relatively independent of $\mathrm{We}_{\mathrm{fd}}$, as suggested by $\mathrm{Eq}$. (8) for an extended range of $\mathrm{We}_{\mathrm{fg}}$ of $30,000-300,000$ in agreement with the bag/shear breakup mechanism. In fact, the variation of density ratio over the present test range also does not have a significant influence on liquid column breakup lengths compared to experimental uncertainties. With these changes, the intermediate region, $W e_{f d}$ of $600-30,000$, is seen to be in reasonably good agreement with behavior expected for the turbulent breakup mechanism from Eq. (7). Finally, the various correlations all seem to be reasonable, with $C_{c}$ in Eq. (3) on the order of unity

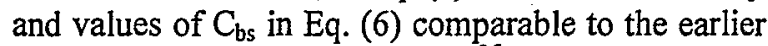
measurements of Hiroyasu et al. ${ }^{25}$ and Chehroudi et al. $^{26}$ In addition, the best fit correlation of the turbulent breakup mechanism also properly indicates liquid column breakup when drop sizes resulting from turbulent primary breakup are comparable to the initial liquid jet diameter; this behavior can be confirmed easily by comparing the Grant and Middleman, ${ }^{6}$ correlations in Figs. 2 and 8.

\section{Fluctuating Breakup Lengths}

The degree of the streamwise fluctuation of liquid column breakup length is illustrated in Fig. 9, based on present measurements. The values of $L_{c}{ }^{\prime} / L_{c}$ are seen to progressively decrease from values of roughly 0.1 at $\mathrm{We}_{\mathrm{fd}}$ of $10^{2}$ to values of roughly 0.01 at We $e_{\text {fd }}$ of $10^{5}$. Referring to Fig. 8 , it is evident that this change mainly comes about due to an increase of $\mathrm{L}_{c}$; with values of $\mathrm{L}_{\mathrm{c}}{ }^{\prime}$ remaining roughly constant over the present test range.

\section{CONCLUSIONS}

This investigation considered the breakup lengths of turbulent liquid jets in still air at standard temperature and pressure with jet exit conditions limited to non-cavitating flows having large 
length/diameter ratio constant area injector passages and jet exit Reynolds and Weber numbers of 5,000140,000 and $100-300,000$, respectively. Major conclusions of the study are as follows:

1. Available measurements of liquid jet breakup lengths due to Chen and Davis, ${ }^{5}$ Grant and Middleman, ${ }^{6}$ and the present investigation are in excellent agreement over the range of conditions where they overlap.

2. The Grant and Middleman, ${ }^{6}$ correlation of liquid jet breakup length, Eq. (1), provides a reasonably good correlation of available measurements for $\mathrm{We}_{\mathrm{fd}}$ of 200-300,000 but this performance is largely an artifact of effects of transition to laminar jet exit conditions and Rayleigh breakup at small $\mathrm{We}_{\mathrm{fd}}$, and transition to aerodynamic bag/shear breakup at large $\mathrm{We}_{\mathrm{fd} \text {. }}$.

3. At moderate $W e_{\mathrm{fd}}$ of $600-30,000$, liquid jet breakup is associated with the turbulent breakup mechanism, given by the correlation of Eq. (7), where liquid column breakup occurs when drop sizes resulting from turbulent primary breakup along the liquid surface become comparable to the diameter of the liquid column itself.

4. At large $\mathrm{We}_{\mathrm{fd}}$, greater than 30,000 , liquid jet breakup is associated with the bag/shear breakup mechanism, given by the correlation of Eq. (8), where the liquid column is distorted in the cross stream direction and small scale turbulence disappears, and breakup occurs by the appearance of bag-like and shear-like structures, analogous to aerodynamic breakup of nonturbulent liquid jets in gaseous cross flows.

\section{ACKNOWLEDGMENTS}

This research was supported by the Office of Naval Research, Grant No. N00014-95-1-0234 under the technical management of E. P. Rood. Initial development of research facilities for this study was carried out under Air Force Office of Scientific Research Grant No. AFOSR F49620-95-1-0364 under the technical management of J. M. Tishkoff.

\section{REFERENCES}

${ }^{1}$ De Juhasz, K.J., Zahn, O.F., Jr., and Schweitzer, P.H., "On the Formation and Dispersion of Oil Sprays," Bulletin No. 40, Engineering Experimental Station, Pennsylvania State University, University Park, PA, 1932.
${ }^{2}$ Lee, D.W., and Spencer, R.C., "Preliminary Photomicrographic Studies of Fuel Sprays," NACA Report No. 424, Washington, D.C., 1933.

${ }^{3}$ Lee, D.W., and Spencer, R.C., "Photomicrographic Studies of Fuel Sprays," NACA Tech. Note 454, Washington, D.C., 1933.

${ }^{4}$ Schweitzer, P.H., "Mechanism of Disintegration of Liquid Jets," J. Appl. Phys. Vol. 8, 1937, pp. 513-521.

${ }^{5}$ Chen, T.-F., and Davis, J.R., "Disintegration of a Turbulent Water Jet," I. Hyd. Div., Vol. 1, 1964, pp. 175-206.

${ }^{6}$ Grant, R.P., and Middleman, S., "Newtonian Jet Stability," AIChE J., Vol. 12, 1966, pp. 669-678.

'Phinney, R.E., "The Breakup of a Turbulent Jet in a Gaseous Atmosphere," I. Fluid Mech., Vol. 60, 1973, pp. 689-701.

${ }^{8}$ McCarthy, M.J. and Malloy, N.A., "Review of Stability of Liquid Jets and the Influence of Nozzle Design," Chem. Engr. J., Vol.7, 1974, pp. 1-20.

${ }^{9}$ Hoyt, J.W., and Taylor, J.J., "Waves on Water Jets," J. Fluid Mech., Vol. 88, 1977, pp. 119123.

${ }^{10}$ Hoyt, J.W., and Taylor, J.J., "Turbulence Structure in a Water Jet Discharging in Air," Phys. Fluids, Vol. 20, 1977, pp. S253-S257.

${ }^{11}$ Ervine, D.A., and Falvey, H.T., "Behavior of Turbulent Water Jets in the Atmosphere and in Plunge Pools," Proc. Inst. Civ. Eng., Pt. 2, Vol. 83, 1987, pp. 295-314.

${ }^{12}$ Townson, J.M., Free-Surface Hydraulics, 1st ed., Unwin Hyman, London, 1988, Chapt. 6.

${ }^{13}$ Faeth, G.M., "Spray Combustion Phenomena," Twenty-Sixth Symposium (International) on Combustion, The Combustion Institute, Pittsburgh, 1996, pp. 1593-1612.

${ }^{14}$ Wu, P.-K., Tseng, L.-K., and Faeth, G.M., "Primary Breakup in Gas/Liquid Mixing Layers for Turbulent Liquids," Atom. Sprays, Vol. 2, 1992, pp. 295-317. 
${ }^{15}$ Wu, P.-K., Hsiang, L.-P., and Faeth, G.M., "Aerodynamic Effects on Primary and Secondary Spray Breakup," Atom. Sprays, Vol. 3, 1994, pp. 265-289.

${ }^{16}$ Wu, P.-K., Miranda, R.F., and Faeth, G.M., "Effects of Initial Flow Conditions on Primary Breakup of Nonturbulent and Turbulent Round Liquid Jets," Atom. Sprays, Vol. 5, 1995, pp. 175196.

${ }^{17}$ Wu, P.-K., and Faeth, G.M., "Onset and End of Drop Formation Along the Surface of Turbulent Liquid Jets in Still Gases," Phys. Fluids A. Vol. 7, 1995, pp. 2915-2917.

${ }^{18}$ Dai, Z., Chou, W.-H., and Faeth, G.M., "Drop Formation Due to Turbulent Primary Breakup at the Free Surface of Plane Liquid Wall Jets," Phys. Fluids, Vol. 10, 1998, pp. 1147-1157.

${ }^{19}$ Sallam, K.A., Dai, Z., and Faeth, G.M., "Drop Formation at the Surface of Plane Turbulent Liquid Jets in Still Gases," Int. J. Multiphase Flow, in press.

${ }^{20}$ Hsiang, L.-P., and Faeth, G.M., "NearLimit Drop Deformation and Secondary Breakup," Int. J. Multiphase Flow, Vol. 18, 1992, pp. 635-652.

${ }^{21}$ Hsiang, L.-P., and Faeth, G.M., "Drop

Properties After Secondary Breakup," Int. J. Multiphase Flow, Vol. 19, 1993, pp. 721-735.

${ }^{22}$ Hsiang, L.-P., and Faeth, G.M., "Drop Deformation and Breakup Due to Shock Wave and Steady Disturbances," Int. J. Multiphase Flow, Vol. 21, 1995, pp. 545-560.

${ }^{23}$ Wu, P.-K., Kirkendall, K.A., Fuller, R.P., and Nejad, A.S., "Breakup Processes of Liquid Jets in Subsonic Crossflows," J. Prop. Power. Vol. 13, 1997, pp. 64-73.

${ }^{24}$ Mazallon, J., Dai, Z., and Faeth, G.M., "Primary Breakup of Nonturbulent Round Liquid Jets in Gas Crossflows," Atom. Sprays, in press.

${ }^{25}$ Hiroyasu, H., Shimizu, M., and Arai, M., "The Breakup of a High Speed Jet in a High Pressure Gaseous Environment," ICLASS-82, Univ. of Wisconsin, Madison, WI, 1982.

${ }^{26}$ Chehroudi, B., Onuma, Y., Chen, S.-H., and Bracco, F. V. "On the Intact Core of Full Cone Sprays," SAE Paper No. 850126, 1985
Table 1 Summary of test conditions ${ }^{\mathrm{a}}$

\begin{tabular}{lll}
\hline Liquid & Water & Ethanol \\
\hline$\rho_{\mathrm{f}}\left(\mathrm{kg} / \mathrm{m}^{3}\right)$ & 997 & 800 \\
$\rho_{\mathrm{f}} / \rho_{\mathrm{g}}$ & 860 & 690 \\
$\mu_{\mathrm{f}} \times 10^{4}(\mathrm{~kg} / \mathrm{ms})$ & 8.94 & 16.0 \\
$\sigma \times 10^{3}(\mathrm{~N} / \mathrm{m})$ & 70.8 & 24.0 \\
$\mathrm{~d}(\mathrm{~mm})$ & $1.9,4.8$ & 4.8 \\
$\mathrm{u}_{\mathrm{o}}(\mathrm{m} / \mathrm{s})$ & $3-25$ & $23-54$ \\
$\mathrm{Re}_{\mathrm{fd}} \times 10^{-3}$ & $6-136$ & $57-129$ \\
$\mathrm{We}$ & & $500-3000$ \\
$\mathrm{Odd}$ & $2-400$ & 53 \\
$\mathrm{Oh}_{\mathrm{d}} \times 10^{-2}$ & $15-24$ & $200-300$ \\
$\mathrm{~L}_{\mathrm{c}} / \mathrm{d}$ & $50-300$ &
\end{tabular}

${ }^{\mathrm{a}}$ Pressure-atomized injection vertically downward in still air at $99 \pm 0.5 \mathrm{kPa}$ and $297 \pm 0.5 \mathrm{~K}\left(\rho_{\mathrm{g}}=1.16\right.$ $\mathrm{kg} / \mathrm{m}^{3}$ and $\mathrm{v}_{\mathrm{g}}=15.9 \mathrm{~mm}^{2} / \mathrm{s}$ ). Round injector with a rounded entry and a length-to-diameter ratio of $40: 1$.

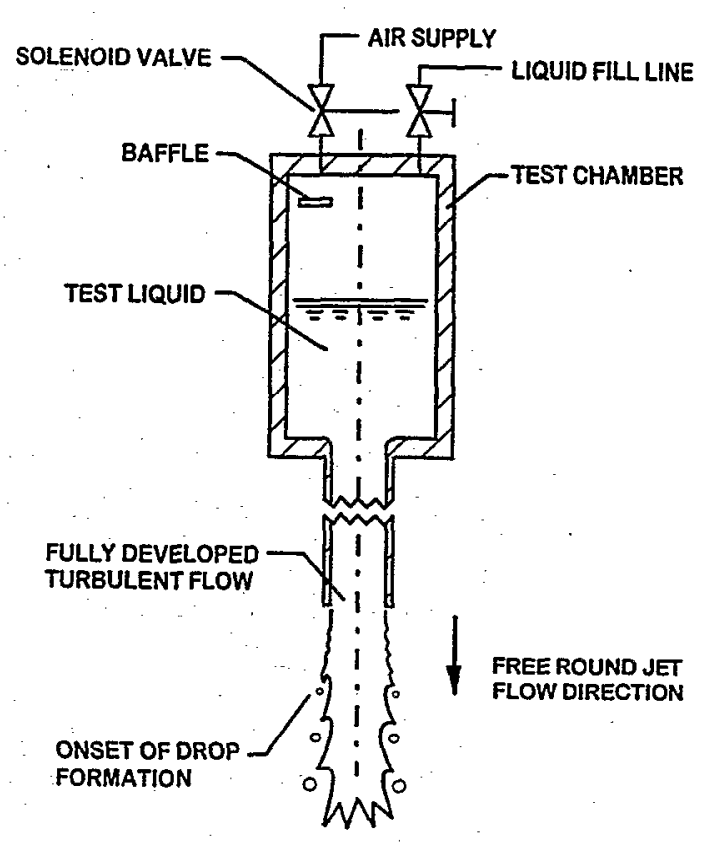

Fig.1 Sketch of the round jet apparatus 


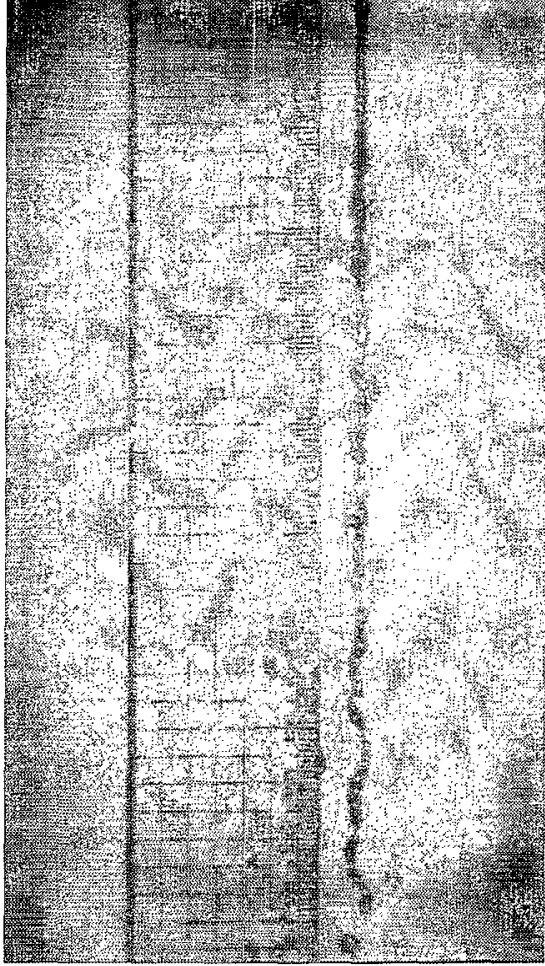

Fig.2 Photograph of round turbulent liquid jet breakup at small Weber number: water jet in still air, $\mathrm{d}=1.9 \mathrm{~mm}, \mathrm{We}_{\mathrm{fd}}=1670, \operatorname{Re}=13690$.

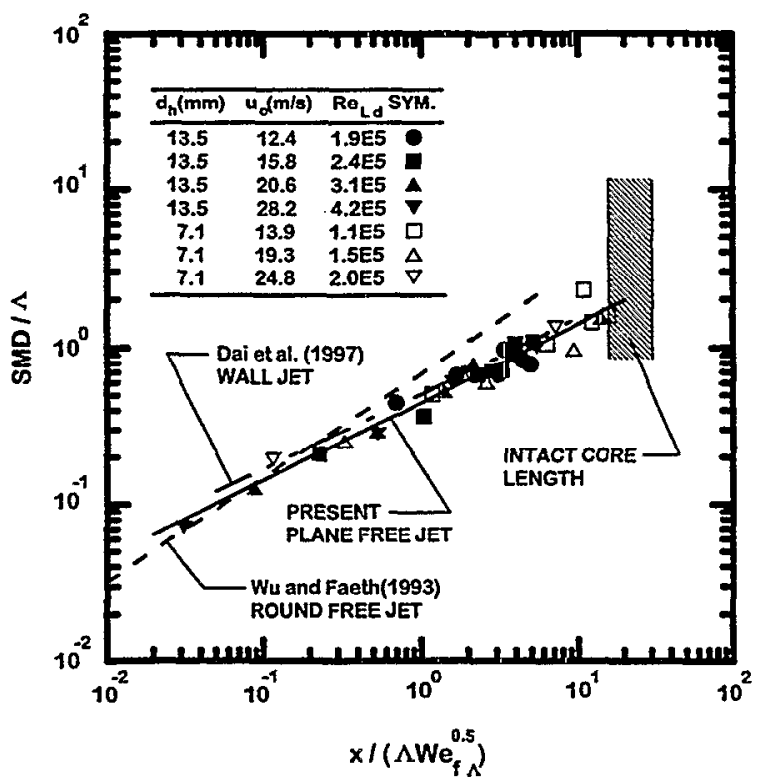

Fig.3 SMD after turbulent primary breakup as a function of distance along the surface. Measurements include results for round free jets from $\mathrm{Wu}$ and Faeth ${ }^{14}$ plane wall jets from Dai et al. ${ }^{18}$ and plane free jets from Sallam et al. ${ }^{19}$ Intact core length correlation for round jets from Grant and Middleman. ${ }^{6}$

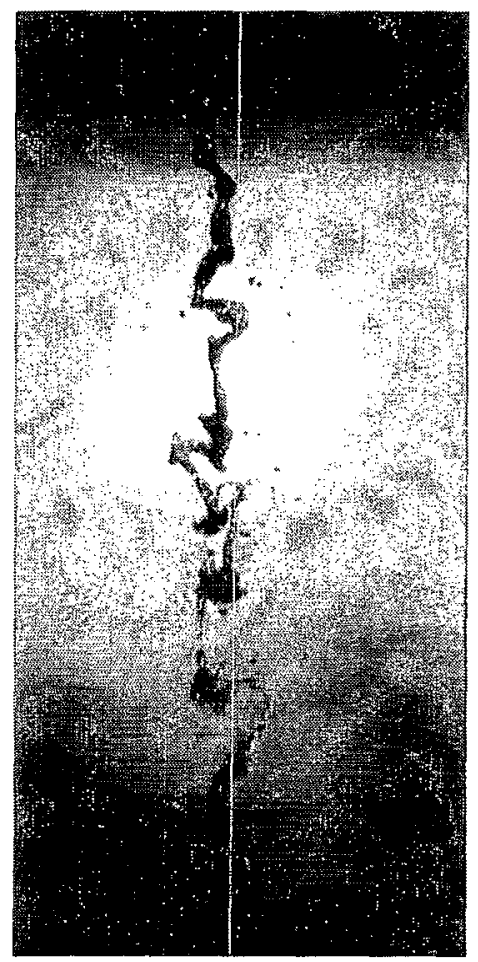

Fig.4 Photograph of round turbulent liquid jet breakup at a large Weber number: water jet in still air, $\mathrm{d}=4.8 \mathrm{~mm}, \mathrm{We}_{\mathrm{fd}}=33100, \operatorname{Re}=97100$.

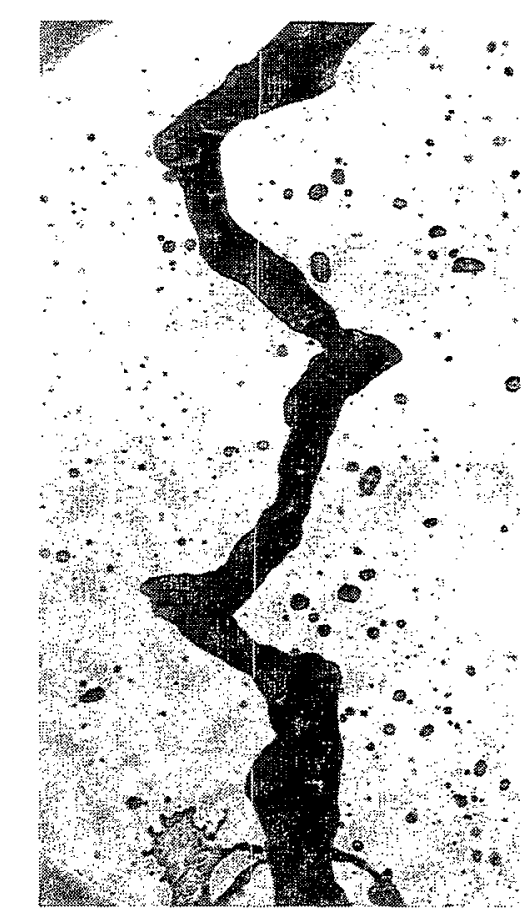

Fig.5 Photograph of large cross stream distortions near the tip of round turbulent liquid jets at large Weber numbers: water jet in still air, $\mathrm{d}=4.8 \mathrm{~mm}$, $\mathrm{We}_{\mathrm{fd}}=33100, \mathrm{Re}=97100$ at a distance of $1010-1060$ $\mathrm{mm}$ from the jet exit. 
(c) 1999 American Institute of Aeronautics \& Astronautics

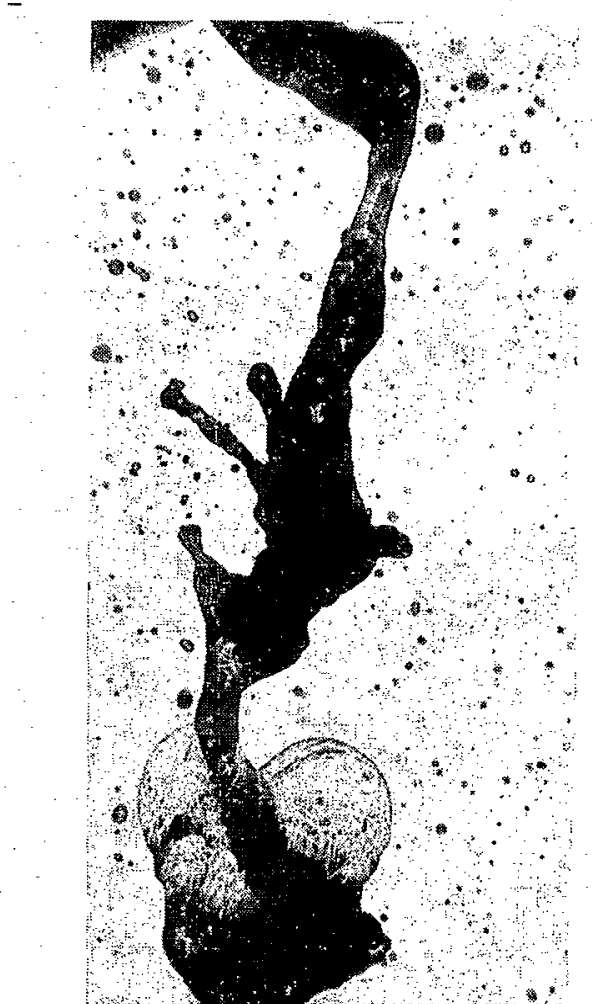

Fig.6 Photograph of the bag-like structures formed in large cross stream distortions near the tip of round turbulent liquid jets at large Weber numbers: water jet in still air, $d=4.8 \mathrm{~mm}, W_{\mathrm{fd}}=33100, \operatorname{Re}=97100$ at a distance of $1040 \mathrm{~mm}$ from the jet exit.

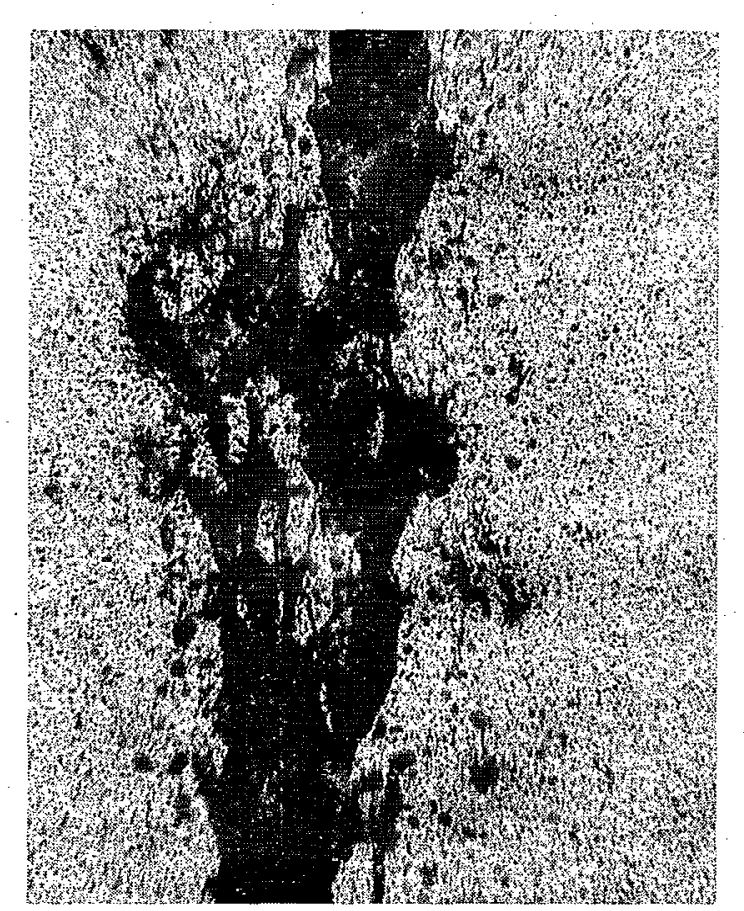

Fig.7 Photograph of shear-type breakup near the tip of round turbulent liquid jets at large Weber numbers: ethanol jets in still air, $\mathrm{d}=0.8 \mathrm{~mm}, \mathrm{We}_{\mathrm{fd}}=$ $271000, \operatorname{Re}=129000$ at a distance of $1300 \mathrm{~mm}$ from the jet exit.

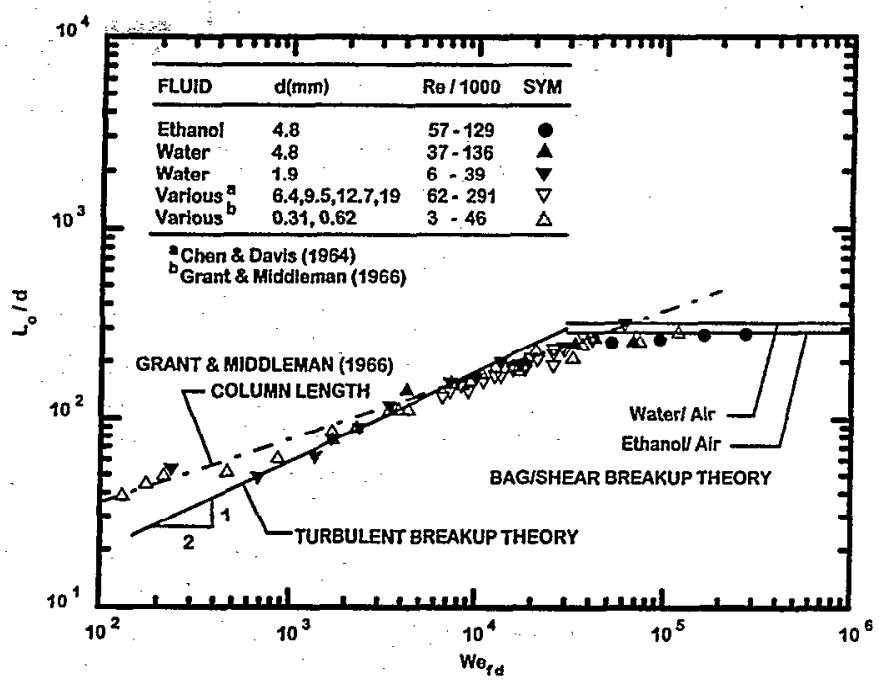

Fig.8 Mean breakup lengths of round turbulent liquid jets in still air plotted according to the turbulent and bag/shear liquid column breakup theories. Measurements of Chen and Davis, ${ }^{5}$ Grant and Middleman ${ }^{6}$ and the present investigation.

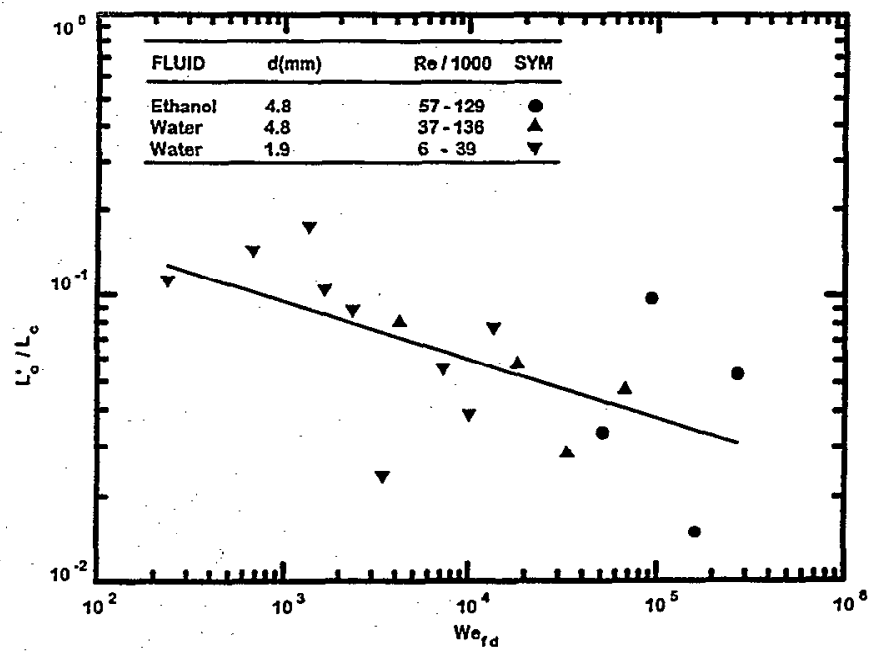

Fig.9 Normalized rms fluctuations of liquid column breakup lengths of round turbulent liquid jets in still air. 